cytotoxic immunosuppression (cyclophosphamide and mesna) Five years later and at approximately 12 weeks pregnant she is confirmed as having squamous cell carcinoma of the right lateral border of the tongue with early local invasion. Not wishing to consider termination of her pregnancy, she underwent surgical resection; which included tracheostomy, right functional/selective neck dissection, manibulotomy, partial glossectomy and oral reconstruction using left radial forearm flap with microvascular reconstruction. Good oral function (speech and swallowing) was restored within two weeks. Potential complications include thrombosis of the microvascular reconstruction secondary to the hypercoagulable state associated with SLE and pregnancy and the complications of surgery itself on the pregnancy, namely miscarriage. The pregnancy proceeded relatively uneventfully to 37 weeks gestation when proteinuric hypertension necessitated induction of labour. The patient remains well, however, some of the scars have healed with hypertrophic/keloid scar formation. There is currently no evidence of recurrence but surveillance is essential and continues.

\section{PM.96 EARLY ONSET SEVERE PRE-ECLAMPSIA AND HELLP SYNDROME AT 21 WEEKS GESTATION}

doi:10.1136/archdischild-2013-303966.177

K Connor, S McGowan, S McNeil. Altnagelvin Area Hospital, Western Health and Social Care Trust, UK, Londonderry, UK

HELLP syndrome; haemolysis, elevated liver enzymes and low platelets may be regarded as a variant or complication of severe preeclampsia occurring in $0.5-0.9 \%$ of all pregnancies and in $10-20 \%$ of cases of severe pre-eclampsia ${ }^{1}$. It is associated with increased maternal morbidity and mortality. ${ }^{2}$ Onset earlier than 28 weeks is rare and there is little published data on maternal and perinatal outcome. ${ }^{13}$ We present a case of severe pre-eclampsia complicated by HELLP syndrome at only 21 weeks gestation.

A 38 year old primiparous patient presented at 21 weeks gestation with headache, visual disturbance and generalised oedema. She was severely hypertensive with significant proteinuria. Following admission she developed haematological and biochemical features of HELLP syndrome with a normal glucose level.

Due to her worsening clinical and haematological condition she was commenced on magnesium sulphate infusion, methyldopa and her pregnancy was terminated with misoprostol therapy. Following 2 cycles of treatment she progressed to a normal vaginal delivery of an 18 week size stillborn male.

After delivery there was marked improvement in blood pressure and haematological markers. Postnatally labetolol controlled blood pressure well. Investigations for underlying pathology included; anti-phospholipid screen, homocysteine, anticardiolipin antibodies, lupus anticoagulant and renal artery and Doppler ultrasound. These were normal. The patient was discharged to primary care on postnatal day 6 and has expressed a keen desire for subsequent pregnancy. As this patients recurrence risk is high ${ }^{4}$ she required counselling for future pregnancy.

\section{REFERENCES}

1. Sibai BM. HELLP Syndrome, UpToDate (Sept 2012), http://www.uptodate.com/ contents/hellp-syndrome (accessed October 2012).

2. Paruk F and Moodley J. Maternal and neonatal outcome in early- and late-onset pre-eclampsia. Seminars in Neonatology 2000;5:197-207.

3. Sibai BM. Evaluation and management of severe preeclampsia before 34 weeks' gestation. American Journal of Obstetrics and Gynecology 2011;205:191-198.

4. August P, Sibai BM. Preeclampsia: Clinical features and diagnosis, UpToDate (Sept 2012), http://www.uptodate.com/contents/preeclampsia-clinical-features-anddiagnosis (accessed October 2012).

\section{PM.97 NEURAL TUBE DEFECTS (NTDS) IN 21ST CENTURY IRELAND: A TERTIARY REFERRAL CENTRE'S EXPERIENCE}

doi:10.1136/archdischild-2013-303966.178

C Monteith, S Cooley, S Coulter- Smith. Rotunda Hospital, Dublin, Ireland

The incidence of NTDs in Ireland has declined over the past two decades from 4.8/1000 births in 1980 to $0.8-1.5 / 1000$ births in $2001^{1}$ Preconceptual folic acid is accepted to reduce the incidence of NTDs however, $50 \%$ of pregnancies are unplanned. ${ }^{2}$ We reviewed the cases over the past three years, their gestation at diagnosis and outcome in conjunction with EUROCAT reporting.

All cases of NTDS were identified from the Fetal Assessment Unit records between 2009-2011. Maternal notes were reviewed to assess demographics and pregnancy outcome.

In total 45 cases of NTD were detected. The overall incidence in our population $1.44 / 1000$ births. Table 1 illustrates the subcategories of NTD diagnosed with the continuation rates. $53.3 \%(n=24)$ delivered in the Rotunda, a further $42.2 \%(n=19)$ didn't re attend for antenatal care and $4.4 \%(n=2)$ returned to other units. Those women who didn't attend for subsequent care were statistically more likely to have diagnosis earlier in the second trimester $(16+3)$ than those who delivered in the Rotunda $(23+1)$ p value $<0.0001$.

There was a significant difference in the average gestation of diagnosis between the group of women who chose to not continue their pregnancies compared to those who do continue. This suggests that early diagnosis affords more options to women of infants with NTD and suggests that second trimester scanning may be warranted, particularly in high-risk groups. ${ }^{3}$ The high incidence of NTD and the poor obstetric outcome again raises the argument for food fortification in Ireland.

\begin{tabular}{lll} 
Abstract PM.97 & Table 1 Neural Tube Defects \\
\hline Neural Tube Defects & $\mathbf{N}(\%)$ & $\%$ that continued pregnancy \\
\hline Anencephaly & $21(47)$ & 38.1 \\
Enencephaly & $2(4)$ & 0 \\
Exencephaly & $4(9)$ & 50 \\
Encephalocoele & $0(0)$ & 0 \\
Myelomeningocoele & $18(40)$ & 88.9
\end{tabular}

\section{REFERENCES}

1. Ward M et al. Folic acid supplements to prevent neural tube defects: trends in East of Ireland 1996-2002. Ir Med J 2004:274-6.

2. Report of the Implementation group on folic acid food fortification to the Department of Health and Children 2008.

3. McAuliffe et al. Ultrasound detection of fetal anomalies in conjunction with firsttrimester nuchal translucency screening: A feasibility study. Am J Obstet Gynecol 2005;193:1260-5.

\section{PM.98 MATERNAL RENAL OUTCOMES FOLLOWING PREGNANCY COMPLICATED BY CHRONIC KIDNEY DISEASE STAGES 3-5}

doi:10.1136/archdischild-2013-303966.179

1,3 $\underline{\mathrm{L} \text { Webster, }}$ 1,2P Webster, 1,2L Lightstone. 'Imperial College Healthcare NHS Trust, London, UK; ${ }^{2}$ Imperial College University, London, UK; ${ }^{3}$ King's College University, London, UK

Objectives To establish the effect of pregnancy on deterioration of renal function in women with Chronic Kidney Disease (CKD) stages $3-5$ attending the renal antenatal clinic.

Methods All women with excretory renal dysfunction (creatinine $>110 \mu \mathrm{mol} / \mathrm{L}$ or eGFR $<60 \mathrm{ml} / \mathrm{min}$ ) prior to pregnancy were identified from the Obstetric-Renal database. Outcomes assessed 